\title{
Using Operations Research to Plan the British Columbia Registered Nurses' Workforce
}

\section{La recherche opérationnelle comme outil de planification de la main-d'œuvre infirmière en Colombie-Britannique}



by MARIEL S. LAVIERI, MSC

$\mathrm{PhD}$ Candidate

Sauder School of Business

University of British Columbia

Vancouver, BC

SANDRA REGAN, RN, MSN, MALS

$\mathrm{PhD}$ Candidate

School of Nursing

University of British Columbia

Vancouver, BC

MARTIN L. PUTERMAN, PHD

Advisory Board Professor of Operations

Sauder School of Business

University of British Columbia

Vancouver, BC

PAMELA A. RATNER, RN, PHD

Professor \& Michael Smith Foundation for Health Research Senior Scholar

School of Nursing

University of British Columbia

Vancouver, BC 


\begin{abstract}
The authors explore the power and flexibility of using an operations research methodology known as linear programming to support health human resources (HHR) planning. The model takes as input estimates of the future need for healthcare providers and, in contrast to simulation, compares all feasible strategies to identify a long-term plan for achieving a balance between supply and demand at the least cost to the system. The approach is illustrated by using it to plan the British Columbia registered nurse (RN) workforce over a 20-year horizon. The authors show how the model can be used for scenario analysis by investigating the impact of decreasing attrition from educational programs, changing $\mathrm{RN}$-to-manager ratios in direct care and exploring how other changes might alter planning recommendations. In addition to HHR policy recommendations, their analysis also points to new research opportunities.
\end{abstract}

\title{
Résumé
}

Les auteurs examinent le potentiel et la souplesse d'une méthodologie de recherche opérationnelle, soit la programmation linéaire, pour faciliter la planification des ressources humaines dans le domaine de la santé. Le modèle utilise, comme données d'analyse, les estimations des besoins à venir des fournisseurs de services de santé et, contrairement à la méthode de la simulation, il compare entre elles toutes les stratégies réalisables afin de déterminer un plan à long terme qui assure l'équilibre entre l'offre et la demande, et ce, aux coûts les plus bas possible pour le système analysé. Les auteurs montrent le fonctionnement de cette approche en procédant à la planification de la main-d'ouvre des infirmières enregistrées en ColombieBritannique sur une période de 20 ans. Ils font voir comment le modèle peut servir à analyser différents scénarios, en évaluant l'impact d'une baisse de l'attrition dans les programmes de formation ou d'une modification du ratio infirmières-gestionnaires dans les soins directs. Ils examinent également d'autres types de changements qui pourraient affecter les recommandations en matière de planification. En plus de recommandations sur les politiques des ressources humaines de la santé, leur analyse propose de nouvelles opportunités de recherche dans ce domaine.

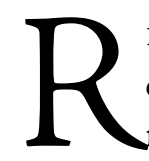
EGISTERED NURSES (RNs) REPRESENT THE LARGEST GROUP OF HEALTHcare providers and are among the 10 occupations with the largest expected number of employment openings in British Columbia (BC) over the next 10 years (BC Statistics 2003). Canada, like many countries, is experiencing a shortage of RNs that is projected to worsen over the next decade. This projected shortage is due, in part, to the growth in need for healthcare services by the Canadian population 
as well as the increased attrition of an aging workforce (Basu and Halliwell 2004). British Columbia's RNs are the oldest RNs, on average, in the country, and the province has the largest percentage of over-45-year-old nurses (CIHI 2006). The large number of RNs expected to retire in the next decade, along with the repercussions of reductions in education seats in the 1990s, have created a significant imbalance between those entering the profession and those leaving (HRSDC and BC Ministry of Advanced Education 2005; O'Brien-Pallas et al. 2003).

Various approaches have been used to estimate the supply of RNs required to meet future demand. However, most approaches rely heavily on supply-side projections, assume current patterns of utilization and seldom include the impact of policy decisions on supply (O'Brien-Pallas et al. 2001). Estimates based on a cohort analysis conducted by the Canadian Nurses Association predict that Canada will be short between 78,000 and 113,000 RNs in the next decade (CNA 2002). Given this projected deficit, strategies addressed specifically to those entering the profession and those who will be retiring from the profession are particularly important. Increasing education seats is considered a key strategy to address the shortage; "governments must be engaged immediately with schools and employers, educating health professionals to put in place the human and physical resources to accommodate more students" (Villeneuve and MacDonald 2006: 101). Yet the number of students that should or could be accommodated is an open question.

Education seats are not the only consideration in planning human resources. Multiple factors influence the supply of, and demand for, RNs, including attrition (short-term leaves, premature leave from the profession and retirement), changes in the workplace (e.g., availability of employment positions and contractual requirements such as hours worked), the availability of personnel in leadership or management roles, the skill mix and task delegation of all healthcare providers, how demand is defined (whether based on current utilization patterns or population healthcare needs) and productivity (availability of support staff and other aids).

Governmental and employers' policies also play an important role in planning human resources. The need to examine how policy decisions made in one sector of the healthcare system can influence other sectors is an issue that is rarely considered. For example, a decision to increase education seats should be commensurate with the availability of employment positions. Studies have indicated that the availability of full-time employment is a factor in whether recently graduated $\mathrm{RNs}$ remain in the province (CRNBC 2006).

Recruitment and retention strategies are another key feature of planning human resources. A growing body of literature has identified the significance of workplace characteristics for $\mathrm{RN}$ retention. In their synthesis of research and other literature on nursing and work, Baumann and colleagues (2001) identified features of the work environment related to perceived quality, including the availability of personnel in 
leadership or management positions and an emphasis on promoting recruitment and retention. Examining the influence of various strategies on the overall supply of RNs is an important element of planning (Kephart et al. 2004).

We developed a comprehensive model that compares feasible strategies and identifies the optimum long-term plan of achieving a supply-demand balance at the least cost to the system based on the estimated need for RNs. We apply this modelling approach to planning British Columbia's RN workforce.

\section{The Problem}

Most modelling approaches tend to be static - one-time - projections of future supply. However, policy decisions are constantly influencing changes in the supply of and demand for RNs, and those decisions can have significant effects on planning. Modelling approaches that can unify supply and demand variables and that are further enhanced by adding contextual factors - such as the costs associated with proposed strategies - may further enrich the models and provide important evidence to evaluate decisions about human resources.

\section{Nursing in British Columbia}

There are 18 educational institutions offering basic or entry-level registered nursing education programs in universities and colleges in British Columbia (CRNBC 2007). With the exception of one program that requires advanced standing (i.e., it admits only students who already hold a degree or who have completed a specified number of credits towards the third year of a baccalaureate program), the educational programs are four years in length.

A small percentage of students discontinue their education before graduation - yearly attrition rates depend on the year of enrolment. A small percentage of those who complete their education leave the province or do not register with the provincial regulatory body. Graduates must pass the Canadian Registered Nurse Examination to be eligible for registration. After acquiring relevant experience, and possibly additional education, direct care RNs may choose to work in entry-level management positions (e.g., clinical resource nurses, assistant managers, managers or supervisors) and later in senior-level management positions (e.g., directors, assistant directors, associate directors or executives). Some RNs may leave the profession permanently or for a period of time (parental leaves are a common reason); attrition rates are highly dependent on age (Kazanjian et al. 1986).

In addition to the graduates of British Columbia's schools of nursing, RNs migrate from other provinces and countries. $\mathrm{BC}$ is considered a destination province (net importer) and, historically, RNs from other provinces or countries have accounted for 
between $40 \%$ and $50 \%$ of new RNs (CRNBC 2006). We assume that the province will continue to attract RNs from outside for the foreseeable future, although the actual number of RNs may decrease with the global shortage of nurses. In the case of an insufficient supply of RNs in British Columbia, our model assumes that it is possible to recruit RNs from elsewhere. This is constrained by the availability of RNs willing to move to the province and the high costs of recruitment, such as the payment of recruitment bonuses or relocation expenses and orientation costs (Weber 2005). Table 1 provides additional information about British Columbia's $\mathrm{RN}$ workforce and population.

TABLE 1. BC's employed registered nurses' demographics and population statistics, 1997-2005

\begin{tabular}{|c|c|c|c|}
\hline & 1997 & 2001 & 2005 \\
\hline $\begin{array}{l}\text { Demographics of employed } \\
\text { registered nurses* }\end{array}$ & $(\mathbf{N}=27,964)$ & $(\mathbf{N}=27,375)$ & $(\mathbf{N}=27,8 \mid 4)$ \\
\hline Number per 10,000 population & 70.2 & 66.7 & 65.3 \\
\hline Average age (national average) & $43.3(42.4)$ & $44.8(43.7)$ & $46.4(44.7)$ \\
\hline \multicolumn{4}{|c|}{ Area of responsibility (Number [\%]) } \\
\hline Direct care & $25,723(92.0)$ & $24,568(89.7)$ & $24,956(89.7)$ \\
\hline Administration & $998(3.6)$ & $1,135(4.1)$ & $1,162(4.2)$ \\
\hline Education & $1,010(3.6)$ & I, $148(4.2)$ & $1,386(5.0)$ \\
\hline Research & $146(0.5)$ & $194(0.7)$ & $235(0.8)$ \\
\hline Not stated & $87(0.3)$ & $330(1.2)$ & $75(0.3)$ \\
\hline \multicolumn{4}{|l|}{ Position (Number [\%]) } \\
\hline Staff nurse/Community health nurse & $22,770(81.4)$ & $21,819(79.7)$ & $21,965(79.0)$ \\
\hline Management & $2,124(7.6)$ & $2,010(7.3)$ & $2,119(7.6)$ \\
\hline Other/Not stated & $3,070(11.0)$ & $3,546(13.0)$ & $3,730(13.4)$ \\
\hline \multicolumn{4}{|l|}{ Place of work (Number [\%]) } \\
\hline Hospital & $18,156(64.9)$ & $17,599(64.3)$ & $17,336(62.3)$ \\
\hline Community & $3,013(10.8)$ & $3,273(12.0)$ & $3,97 \mid(\mid 4.3)$ \\
\hline Nursing home & $2,333(8.3)$ & $3,653(13.0)$ & $3,37 \mid(\mid 2.1)$ \\
\hline Other/Not stated & $4,462(16.0)$ & $2,940(10.7)$ & $3,136(11.3)$ \\
\hline \multicolumn{4}{|c|}{ Source of new RN's' (Number [\%]) } \\
\hline BC schools of nursing & $670(46.9)$ & $572(46.7)$ & $857(55.0)$ \\
\hline Other provinces & $601(42.1)$ & $371(30.3)$ & $405(26.0)$ \\
\hline Other countries & $158(\mid 1.1)$ & $282(23.0)$ & $297(19.1)$ \\
\hline \multicolumn{4}{|l|}{ BC population estimates $\#$} \\
\hline Total population & $3,948,544$ & $4,078,447$ & $4,257,833$ \\
\hline
\end{tabular}

\footnotetext{
* Canadian Institute for Health Information, based on the number in the registry actively employed in nursing (2002, 2006).

+ College of Registered Nurses of British Columbia.

\# Statistics Canada.
} 


\section{The Approach}

Our approach was to formulate the planning problem as a linear program (LP), a powerful mathematical tool that enables "the planning of activities to obtain an optimal result, i.e., a result that reaches the specified goal best among all feasible alternatives" (Hillier and Lieberman 2001: 24).

A linear program has three main components: decision variables, an objective function and a set of constraints. Solving it determines values for the decision variables so that the objective function is as high or as low as possible (depending on whether the decision-maker seeks to minimize or maximize the objective) while simultaneously ensuring that all constraints are satisfied. Linear programming is different from simulation in that, rather than relying on a lengthy search for a strategy that will both meet a set of requirements and be as good as possible, the mathematical structure of the linear program ensures that this happens. We have provided details of the mathematical formulation of the model elsewhere (Lavieri and Puterman 2008).

Linear programming models can be formulated in MS Excel. Problems as large as those necessary for workforce planning require add-ons. We used the Frontline solver add-on to obtain solutions (Frontline Systems 2007). Finding an optional solution required a few seconds on a personal computer.

The goal of the proposed model is to determine for each year in a specified planning horizon (we used 20), while achieving target staffing levels, (a) the number of first- and third-year nursing students to admit to educational programs, (b) the number of direct care RNs and entry-level managers to recruit from outside the province and (c) the number of RNs to promote each year to minimize the total cost of education, recruitment and annual salary.

The yearly costs that are part of the objective function were calculated as follows. Education cost was the sum of the annual cost of educating each student multiplied by the number of students enrolled in each year after taking into account the number of students accepted and the assumed attrition rates. Furthermore, students admitted into the advanced standing program incur an initial fixed cost per student in addition to their yearly education cost (owing to the prior cost associated with earning the minimum number of completed credits required for admission to the program). We also assumed that a cost is incurred when RNs are promoted into managerial positions (calculated as the total number of RNs promoted multiplied by the promotion cost). Yearly recruitment costs were the product of the number of RNs promoted and the recruitment cost. Lastly, we calculated annual salaries by multiplying the average annual salaries at each position by the number of RNs in each position each year. Total costs were the sum of all these costs over the planning horizon. We acknowledge that this figure only approximates the total costs incurred by the system, and stress that this function is used only to ensure that no more RNs are educated, promoted or recruited than are needed in the long erm. It is possible to analyze the role that these cost assumptions play in the solution. 
The length of the horizon was determined in consideration of policy needs, the availability and reliability of the data and the desire to provide a solution over a sufficient period to incorporate the future implications of current decisions. However, the model should be updated as new data become available.

TABLE 2. Model inputs

\begin{tabular}{|c|c|c|c|}
\hline $\begin{array}{l}\text { Health human } \\
\text { resource element }\end{array}$ & Input & Description & Source \\
\hline Production & Education costs & $\begin{array}{l}\text { Annual cost of funding an } \mathrm{RN} \\
\text { education program seat }\end{array}$ & $\begin{array}{l}\text { BC Ministry of Advanced } \\
\text { Education (MAE) }\end{array}$ \\
\hline Production & $\begin{array}{l}\text { Probability of continuing to } \\
\text { completion of education }\end{array}$ & $\begin{array}{l}\text { Fraction of students that continue } \\
\text { in the program each year }\end{array}$ & $\begin{array}{l}\text { UBC School of Nursing; } \\
\text { Pringle and Green (2005) }\end{array}$ \\
\hline Supply & $\begin{array}{l}\text { Probability of passing the } \\
\text { CRNE examination }\end{array}$ & $\begin{array}{l}\text { Fraction of } \mathrm{BC} \text { graduates that pass } \\
\text { the national examination }\end{array}$ & CRNBC (2005) \\
\hline Supply & $\begin{array}{l}\text { Probability of leaving BC } \\
\text { after graduation }\end{array}$ & $\begin{array}{l}\text { Fraction of RNs that do not remain } \\
\text { in the province after graduation }\end{array}$ & CRNBC (2005) \\
\hline Supply & Attrition rates & $\begin{array}{l}\text { Annual probability of permanently } \\
\text { leaving the workforce in the } \\
\text { province }\end{array}$ & $\begin{array}{l}\text { Kazanjian ( } 1986) \text {; O'Brien- } \\
\text { Pallas et al. (2003) }\end{array}$ \\
\hline Supply & Age distribution & $\begin{array}{l}\text { Current demographics of students } \\
\text { and RNs }\end{array}$ & $\begin{array}{l}\text { UBC School of Nursing } \\
\text { (2006); CRNBC (2005); } \\
\text { CIHI (2005) }\end{array}$ \\
\hline Deployment & Workforce ratios & Managerial ratios & $\mathrm{CIHI}(2005)$ \\
\hline Deployment & FTE & Full-time equivalents of each RN & $\begin{array}{l}\text { ClHI (2005); Statistics } \\
\text { Canada (2004) }\end{array}$ \\
\hline Financial Resources & Annual salary & Average annual salaries paid in $B C$ & BC Nurses' Union \\
\hline Financial Resources & $\begin{array}{l}\text { Recruitment and turnover } \\
\text { cost }\end{array}$ & $\begin{array}{l}\text { Incentives, orientation and other } \\
\text { recruitment costs incurred per } \\
\text { recruited } \mathrm{RN}\end{array}$ & Weber (2005) \\
\hline Financial resources & $\begin{array}{l}\text { Management education } \\
\text { cost }\end{array}$ & $\begin{array}{l}\text { Cost of training to promote a } \\
\text { direct care RN to a managerial } \\
\text { position }\end{array}$ & MAE \\
\hline Need/Demand & $\begin{array}{l}\text { Ratio of number of RNs to } \\
\text { population }\end{array}$ & \multirow{2}{*}{$\begin{array}{l}\text { Used as an estimate of the } \\
\text { minimum number of RNs needed } \\
\text { in the province per year (should } \\
\text { be replaced by a more elaborate } \\
\text { needs-based model) }\end{array}$} & $\mathrm{CIHI}(2005)$ \\
\hline Need/Demand & Projected BC population & & BC Stats (2006) \\
\hline
\end{tabular}

The model is constrained by targets (i.e., the minimum number of $\mathrm{RN}$ full-time equivalents [FTEs] needed to meet the health needs of the population), the number of RNs that can be recruited each year, the maximum yearly growth of nursing educational programs and the belief that RNs are likely to be assigned to managerial positions only after they have been in a direct care position for a certain number of years. The model also keeps track of the aggregate number of students and RNs in the prov- 
ince by age and by year. These constraints can be adjusted to reflect current and future realities. The key inputs to the model are summarized in Table 2.

Given the limitations of data access and the lack of integrated sources, we encountered various challenges in obtaining the necessary data. Proxies for actual data were used when necessary.

We view our analyses below as an illustration of how this modelling approach can be used to provide policy guidelines, investigate assumptions and set targets. However, the specific numerical values of decision variables are highly sensitive to the model inputs. Using this model in practice would require additional verification of inputs and assumptions, but we strongly believe this approach can provide the answers that policy makers need.

\section{Scenario Analysis}

There are many possible policy changes that could be made to the system. Rather than putting them into practice and later analyzing the impact that they have on the size and age composition of the workforce, we show how our modelling approach can be used on a "What if?" basis to determine the optimal human resources strategy in each case. Five scenarios are analyzed herein. They have been chosen to address current policy concerns and to illustrate how the model could be used for setting policy. In each case, we make the appropriate changes to the model inputs and solve it to find an optimal education, recruitment and promotion policy. We then compare the model output graphically.

\section{Scenario 1 - A baseline scenario}

The first scenario assumes:

+ The goal is to maintain current provider-to-population ratios subject to increasing populations.

- In the first 10 years of the model, the percentage increase in the number of students admitted to university programs is constrained to be the same as the maximum increase that has been observed in the past.

- After entering the workforce, RNs who have completed the advanced standing program have the same attrition rates, by age, as RNs that have completed a standard program.

- When RNs are initially employed, they require time for adjustment to the position (i.e., in their first year of a new position they work 0.8 FTEs to accommodate orientation, mentorship and learning).

- A minimum of 500 direct care RNs move to British Columbia each year.

- There are no restrictions on the maximum number of RNs that can be recruited 
from other provinces and countries in the first year. However, we impose an increased cost associated with bringing new direct care $\mathrm{RNs}$ to the province.

\section{Scenario 2 - Changes in educational program attrition rates}

The second scenario addresses the impact of changes in the proportion of students who continue in their educational program after each year of study. The attrition rates are the ratio of students in two consecutive years of schooling.

Reported attrition rates from nursing educational programs vary widely and have been noted to range between 3\% and 44\% (Pringle and Green 2005). We tested a range of possible attrition rate scenarios. At baseline (Scenario 1), attrition rates of $10 \%$ in the first year and $2 \%$ and $5 \%$ in the second and third years, respectively, were used. In this scenario, we investigated how the optimal policy would change if there were no attrition. Such a scenario might not be realistic, but it shows the impact of reducing educational program attrition rates on other decision variables.

Scenario 3 - Simultaneously change the direct care RN-to-manager ratio and the practising $\mathrm{RN}$ attrition rate

The baseline scenario assumes a direct care $\mathrm{RN}$-to-manager ratio that follows the national average of approximately 50 direct care RNs and four entry-level managers per senior-level manager (CIHI 2006). We chose to investigate the impact of two simultaneous changes to the baseline scenario: reducing the direct care $\mathrm{RN}$-to-manager ratio by $10 \%$ while assuming that the change would reduce the attrition rates of all RNs by $10 \%$. We caution the reader that the effect of reducing $\mathrm{RN}$-to-manager ratios on attrition rates has not been widely studied. Although many researchers acknowledge the importance of managers for direct care $\mathrm{RN}$ retention (Kramer et al. 2004), they do not report the ideal ratio. Therefore, empirical research is needed to determine whether reductions in $\mathrm{RN}$ attrition could be achieved by altering direct care $\mathrm{RN}$-to-manager ratios.

\section{Scenario 4 - Change the length of parental leave}

The length of parental leave entitlement is a controversial topic. Although we do not advocate for longer or shorter parental leaves, we used the model to investigate the impact on recruitment, promotion and training of shortening parental leaves to six months from the 12 months assumed in the baseline scenario. We assumed that the annual fertility rate of $\mathrm{RNs}$ was the same as the population average fertility rate, by age, of all women in British Columbia in 2004 (Statistics Canada 2004). This approach fails to recognize the rate at which male RNs and adoptive parents exercise their parental leave provisions. 


\section{Scenario 5 - Change the $\mathrm{RN}$-to-population ratio}

In the absence of demand variables for the model, we used the RN-to-population ratio as a proxy for demand. There is no consensus, however, on what the "proper" ratio ought to be. As mentioned previously, the model allows for demand to be defined by the decision-maker. For example, if demand is defined by rates of hospital utilization or population healthcare needs, then these variables could be entered. We therefore believe that the model is a complement to a demand-based model that provides more informed estimations of the minimum number of RNs needed to meet the population's health needs in a given year.

Suppose a needs-based model suggested that a reasonable target was to have five fewer people per RN than the baseline, and that in such a case, the attrition rate of RNs was reduced by $15 \%$. Under these assumptions, not only would the total number of direct care RNs increase in the long term, but the increase could be achieved with a lower yearly recruitment rate. Other possible scenarios include a change in the ratio over the planning horizon (which might be associated with changes in the age distribution of the population) or the direct input of the minimum number of RNs needed based on the population's health status or other characteristics.

\section{Results}

Optimal values for the policy variables under the five scenarios are represented in Figures 1 through 4.

Figure 1 shows the total number of direct care RNs available each year in British Columbia under each of the scenarios. The minimum number of RNs required to maintain the current $\mathrm{RN}$-to-population ratio has also been included. Note that in none of the scenarios does the model suggest having exactly the targeted number of $\mathrm{RNs}$ in the first years. This is because planning decisions this year will have long-term implications and consequently affect planning decisions in the future. Note also that in all the scenarios, the rate of increase in the total number of direct care RNs stabilizes after a few years. Also, as the current workforce is older than is optimal, adding RNs early on is necessary to meet future needs for RNs and managers.

Even with an increase of entry-level managers and senior-level managers (Scenario 3), the total number of new RNs that would be needed is lower than if such an increase were accompanied by a reduction in attrition. Furthermore, note that the reduction in duration of parental leave did not have a significant effect on the solution. We also tested a scenario with no parental leave (an extreme scenario acknowledged not to be feasible) and noticed no major difference in the number of students admitted to educational programs or recruitment requirements. This finding may be related to the low fertility rates in the province. However, if it were true that radically reducing parental leave would not reduce the need to educate or recruit new RNs, and if by 
having such a benefit, attrition rates for RNs could be reduced, Scenario 4 supports a decision to increase parental leave from six to 12 months, as was recently done in Canada. We emphasize that to make a decision based on this scenario, other factors involving parental leave (such as the possible association with the fertility rate) would need to be considered.

FIGURE 1. Number of direct care registered nurses per year

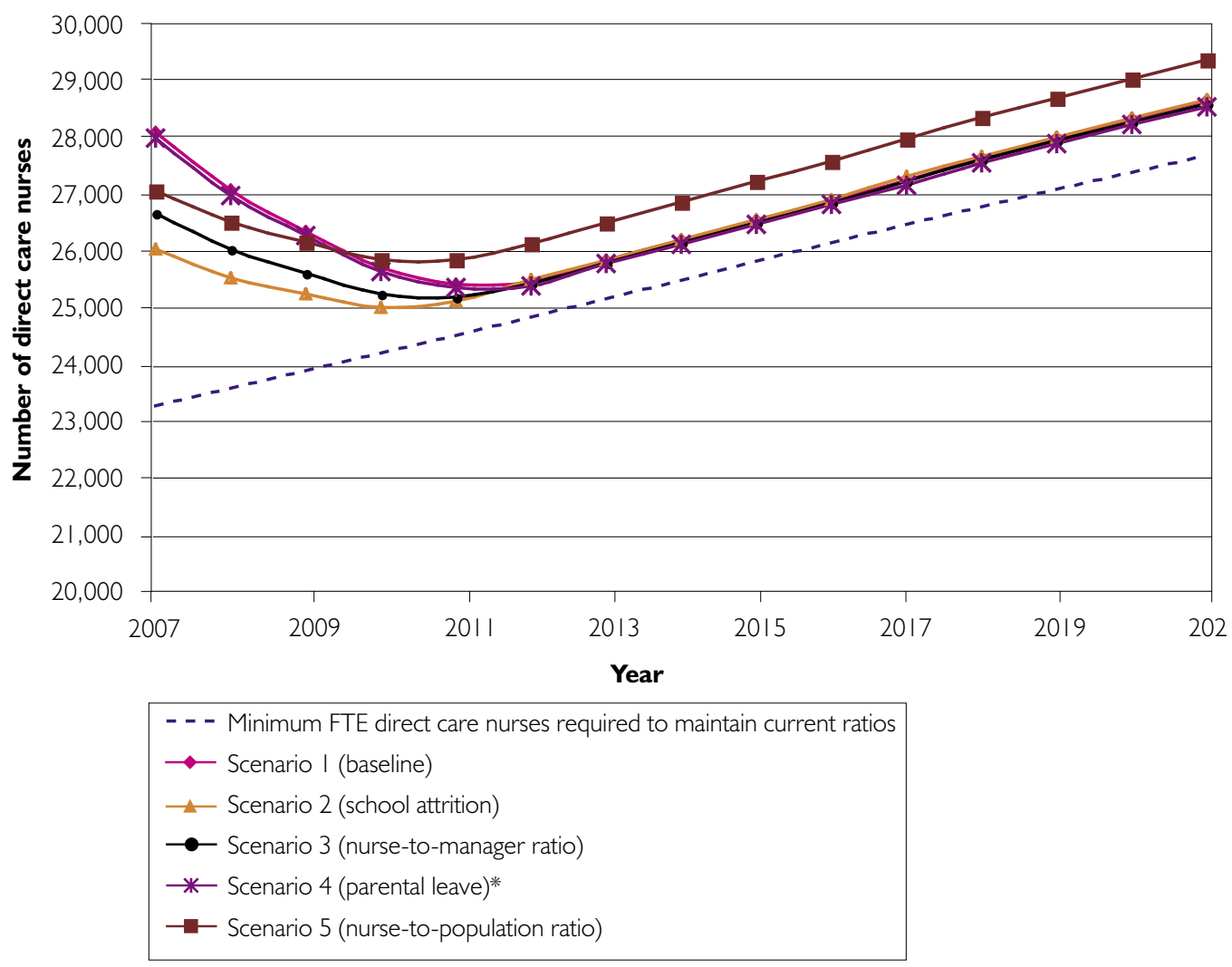

* Scenario 4 (parental leave) is superimposed on Scenario I (baseline).

Figure 2 summarizes yearly recruitment requirements. Observe that a large recruitment of direct care RNs from outside the province is required in all the scenarios, especially in the first year. While the number of direct care RNs recruited is much lower after the first year, note that the recruitment number of direct care RNs is still elevated up to the year 2016. This situation occurs because the current workforce is not sufficient to meet short-term needs given the current $\mathrm{RN}$ age distribution and attrition rates. Although we assume that a higher cost is associated with the recruitment of RNs from outside the province compared with the education of new RNs within the province, recruiting RNs externally provides a "quick fix" to the shortage 
problem. That is, changing the number of students that are admitted to nursing educational programs will have an impact only once those students have completed their programs (either two or four years after their admission to the program). However, with a lower attrition from the programs (Scenario 2), we also observe a lower initial recruitment of direct care RNs and senior-level managers from out of province.

FIGURE 2. Recruitment policies for various scenarios
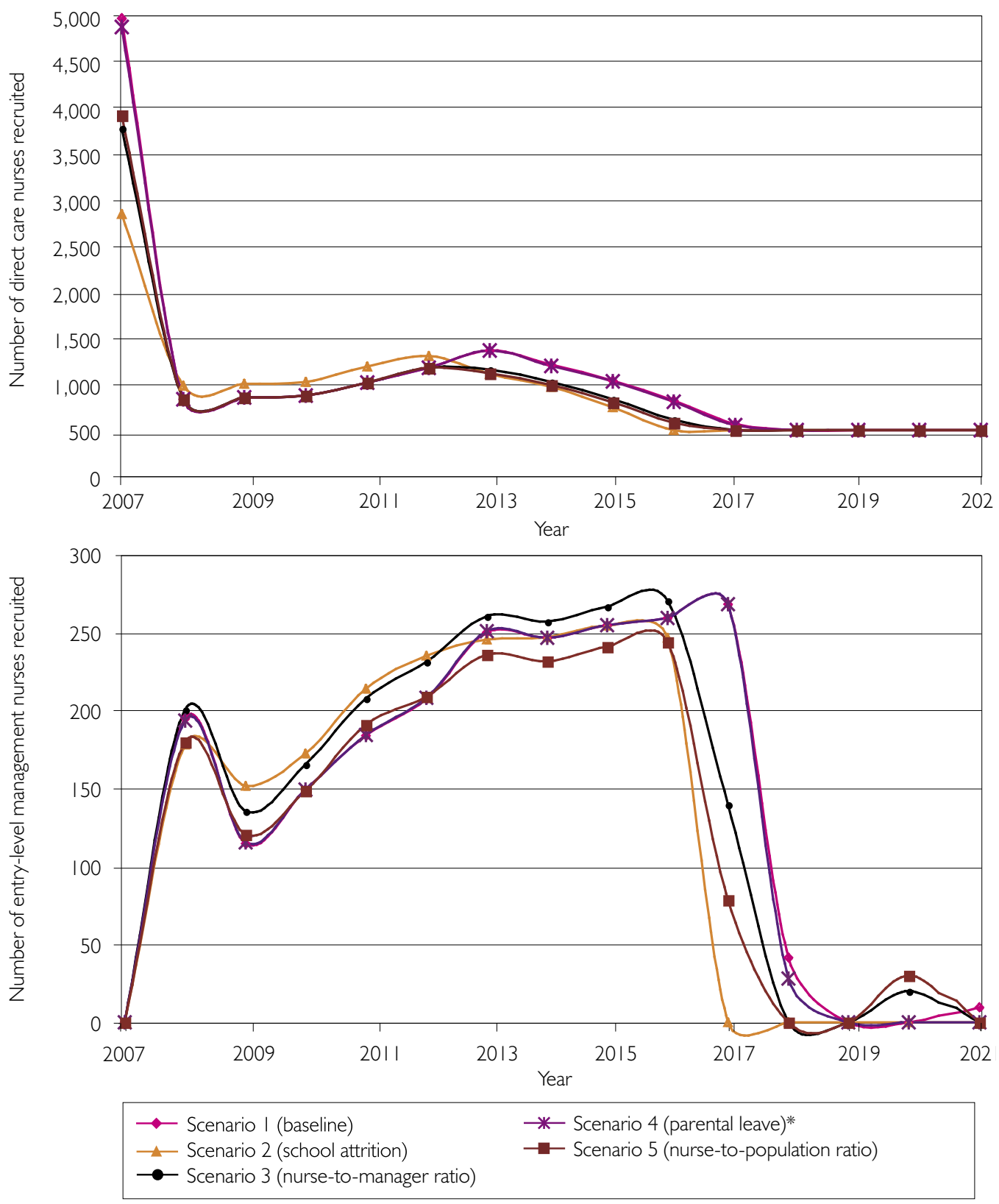

* Scenario 4 (parental leave) is superimposed on Scenario I (baseline). 
Using Operations Research to Plan the British Columbia Registered Nurses' Workforce

In addition, the model is highly sensitive to the attrition rates of direct care RNs. While Scenario 5 leads to a greater RN population (as seen in Figure 1), from Figure 2 we note that the higher targets are achieved with lower recruitment needs. This finding is due to our assumption that an increase in the number of RNs per population will decrease attrition rates of direct care RNs.

FIGURE 3. Admission policies for various scenarios
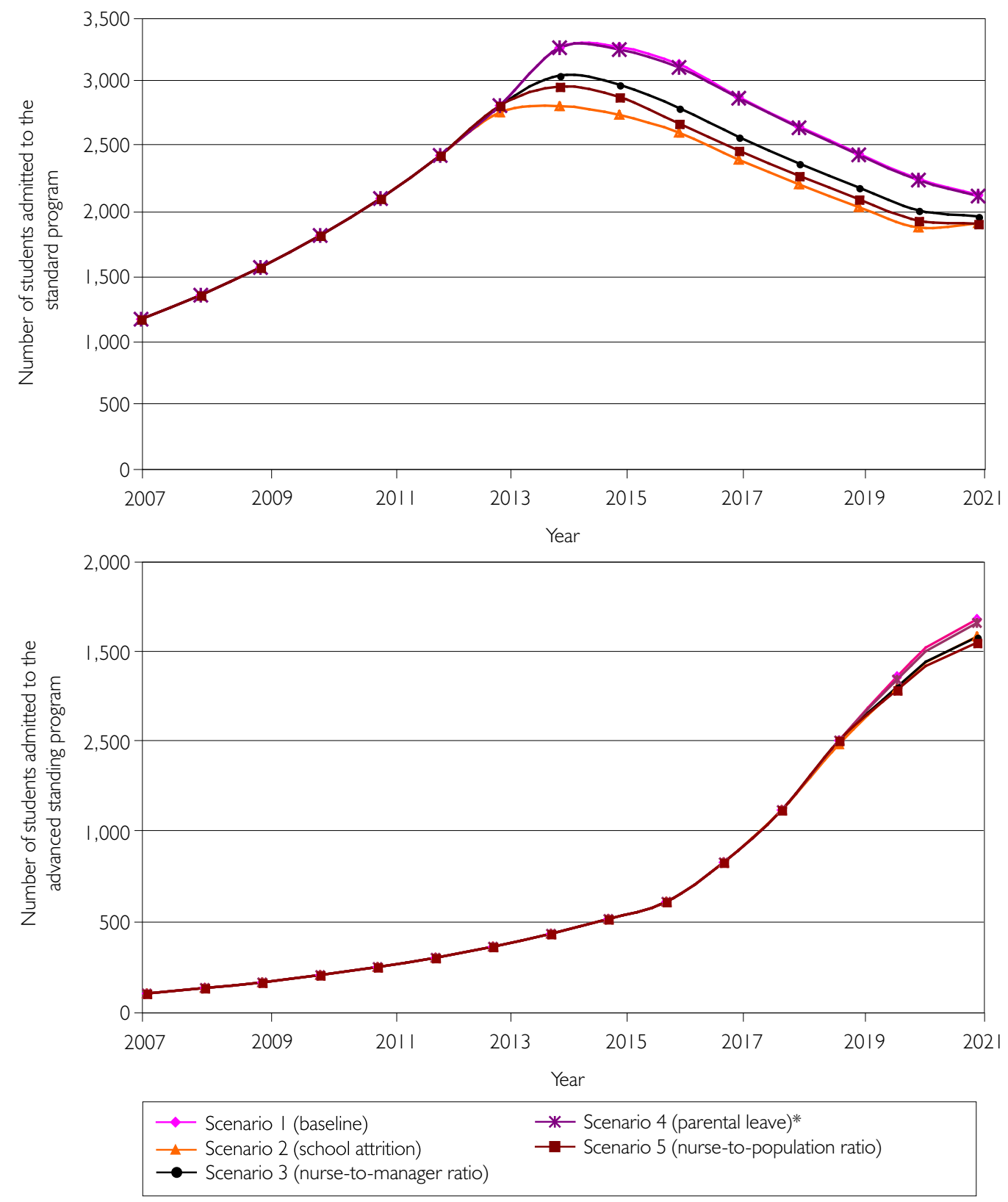

* Scenario 4 (parental leave) is superimposed on Scenario I (baseline). 
We stress that we are not advocating a massive recruitment of RNs from outside the province in the near future (a measure that would have social and ethical implications), but instead are using the model to show that to achieve desired target nurse-population ratios this is necessary. Alternatives could be identified by adding a constraint on the number of RNs recruited early on and relaxing short-term RN-topopulation ratios.

FIGURE 4. Promotion policies for various scenarios
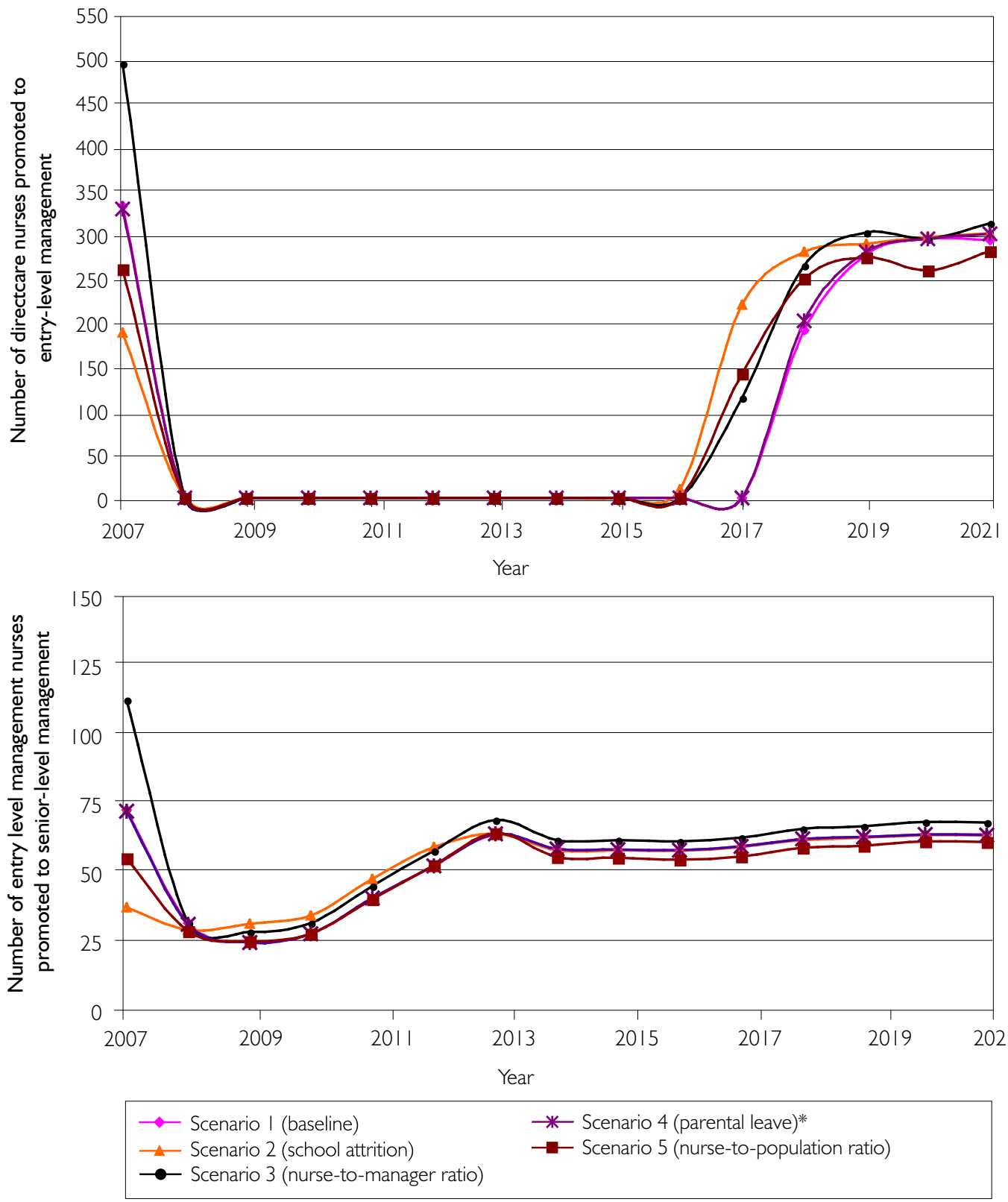

* Scenario 4 (parental leave) is superimposed on Scenario I (baseline). 
Figure 3 summarizes the total number of students admitted into BC nursing educational programs. Note that the number of students admitted in the first years of the model is not greatly affected by the parameters analyzed in the scenarios. This low impact occurs because the capacity of the schools - as represented by physical space, availability of preceptors, clinical placements for students and number of faculty - is a limiting factor in our current system (Pringle et al. 2004). Although the number of students admitted into both types of educational programs must first increase - given that the current programs are not sufficient to meet the assumed demand for RNs, and that a limit on the yearly increase of both types of programs is imposed - after a certain point, the number of students to be admitted into standard programs starts to decrease (up to a certain point) while the number of students to be admitted into the advanced standing program keeps increasing. This situation arises despite our assumption that students admitted to the advanced standing program are older than those students admitted to standard programs, and that a fixed cost equivalent to two years of education in a nursing program (in addition to their nursing education costs) is accrued by every student admitted to the advanced standing program. An explanation of this result might be the lower attrition rates of third-year students in relation to first-year students or the end effects of a 20-year planning horizon.

Figure 4 displays promotion patterns under each scenario. Although the number of RNs promoted from entry-level to senior-level management appears stable, that is not the case for the promotion of direct care RNs to entry-level management. An explanation for the behaviour of the model might be that no limits were imposed on the minimum number of RNs to be promoted. Therefore, because of the insufficient current supply of direct care RNs in the province, the model suggests keeping as many direct care RNs as possible and recruiting to fill entry-level management positions in the first few years.

\section{Discussion}

The analysis above shows that one potential solution to the long-term $\mathrm{RN}$ shortage is to increase the number of students admitted to an advanced standing educational program while increasing the number of students admitted to standard educational programs at first, but only to a certain point. Although we assumed that students admitted to the advanced standing program are older than those students admitted to standard programs, we also assumed that once they graduate, their attrition from the profession will depend only on their age and not on their type of education. Empirical evidence should be collected to verify this assumption. Furthermore, a large initial recruitment of RNs from outside the province is required under all scenarios. A possible expansion to the model would consequently be to include a limit on the minimum number of direct care RNs to be promoted, or to increase attrition rates of RNs if no 
such limits are available.

In the first few years, the required number of direct care RNs promoted to entrylevel management is small given the expected shortage of direct care RNs. Research has indicated that a sufficient supply of managers is necessary and beneficial for recruitment and retention of direct care RNs (Kramer and Schmalenberg 2002). We could not find research evidence that would point to the "optimal" direct care RNto-manager ratio. We used national average ratios of direct care RNs to managers. Further research in this area might be useful to assist decision-makers in developing succession plans for managers and senior-level administrators.

Attrition rates vary across nursing education programs (Pringle and Green 2005). In the model, we applied a conservative attrition rate for the nursing educational programs. The model indicated that attrition plays a significant role in the supply of new graduate RNs. An examination of the predictors of successful completion (Patrick 2001; Wharrad et al. 2003), along with the possible reasons for attrition and strategies to reduce it (Pringle and Green 2005; Scott 2004), may have a significant impact on the entire $\mathrm{RN}$ workforce population.

Among the challenges we experienced in applying the model were the limited availability and accessibility of data about the current workforce and the lack of a comprehensive and coordinated data repository or single database on RNs. Romanow (2002: xxix) highlighted that "we cannot expect to keep improving the health care system if we do not have the necessary information to measure and track results." Although data about RNs and physicians are relatively accessible when compared with information about the other health professions, there continue to be significant limitations in the data collected and their availability. Many recent reports have recognized these difficulties and offered recommendations for improved data collection on health human resources (Romanow 2002; Dault et al. 2004; Kephart et al. 2004; Task Force Two 2005). We made various assumptions about the model parameters such as direct care $\mathrm{RN}$-to-manager ratios, the minimum number of RNs required in the province per year and so forth. Future research would help establish a better empirical basis for the assumptions.

Although the model provides directions, other changes must occur in the system so that model recommendations can be implemented. For example, constraints that limit the capacity of nursing educational programs to expand, such as the shortage of nursing faculty, need to be addressed.

This model could also be used to analyze the impact of policy initiatives, such as changes in the composition of multidisciplinary teams and the expanding scope of practice of RNs and licensed practical nurses. Assuming that workforce skill mix will have an impact on the total demand for RNs, this scenario could be accommodated by changing the demand parameters over the years (which are an input to our model) in a similar way as discussed in Scenario 5. Another possibility would be to incorporate other categories (such as physicians or other nursing groups) in our model. This pro- 
jection would require access to the necessary data to populate such a model.

\section{Conclusions}

We acknowledge that our approach has various limitations, given the assumptions highlighted in this paper and the challenges encountered in gathering the necessary data. Nonetheless, we believe that our approach is useful to decision-makers. We recommend that greater emphasis be placed on accurate collection and calculation of the parameters that have the greatest effect on the decision-making process. Using the model, we have shown that attrition rates from educational programs and from the profession have significant effects on recruitment and training. Consequently, decisionmakers should consider initiatives that promote better estimation of and reductions in such attrition, such as changes in nurse-manager ratios. Further, we have identified several promising new research questions. With the movement towards needs-based models, our approach provides a systematic way to determine how best to meet the identified needs and how changing conditions affect the workforce plan over the long term.

\section{ACKNOWLEDGEMENTS}

We wish to thank the organizations listed in this paper for providing data for our study. Any errors in the data analysis or interpretations are the authors'.

Mariel S. Lavieri acknowledges funding support from the Natural Sciences and Engineering Research Council of Canada, the Itoko Muraoka Fellowship and the Bonder Scholarship for Applied Operations Research in Health Services.

Martin L. Puterman acknowledges funding support from the Natural Sciences and Engineering Research Council of Canada and the Mathematics of Information Technology and Complex Systems.

Sandra Regan acknowledges funding support from Canadian Institutes of Health Research - TUTOR-PHC Fellowship and Doctoral Research Award, Michael Smith Foundation for Health Research Senior Graduate Studentship, Western Regional Training Centre and Canadian Nurses Foundation Doctoral Scholarship.

Pamela A. Ratner acknowledges funding support from the Michael Smith Foundation for Health Research.

Correspondence may be directed to: Mariel S. Lavieri, MSc, PhD Candidate, Management Science, Sauder School of Business, University of British Columbia, 2053 Main Mall, Vancouver, BC V6T 1Z2; tel.: 604-827-5286; e-mail: mariel. lavieri@sauder.ubc.ca. 


\section{REFERENCES}

Basu, K. and K. Halliwell. 2004 (May 4). "Projecting the HHR Impacts of Demographic Change." Health Policy Research Bulletin 8: 17-21.

Baumann, A., L. O’Brien-Pallas, M. Armstrong-Stassen, J. Blythe, R. Bourbonnais, S. Cameron, D. Irvine Doran, M. Kerr, L. McGillis Hall, M. Vezina, M. Butt and L. Ryan. 2001. "Commitment and Care: The Benefits of a Healthy Workplace for Nurses, Their Patients and the System. A Policy Synthesis." Ottawa: Canadian Health Services Research Foundation.

BC Statistics. 2003 (June 6). “BC Occupational Employment Projections, 2001-2011.” Labour Force Statistics.

BC Statistics. 2006. "Projections - Total Age Group - Query Results." Population Projections - BC and Regional. Retrieved September 25, 2008. <http://www.bcstats.gov.bc.ca/data/pop/ pop/popproj.asp\#admin>.

Canadian Institute for Health Information (CIHI). 2002. "Supply and Distribution of Registered Nurses in Canada, 2001." Ottawa: Author

Canadian Institute for Health Information (CIHI). 2005. "Workforce Trends of Registered Nurses in Canada, 2004." Ottawa: Author.

Canadian Institute for Health Information (CIHI). 2006. "Workforce Trends of Registered Nurses in Canada, 2005." Ottawa: Author.

Canadian Nurses Association (CNA). 2002."Planning for the Future: Nursing Human Resource Projections." Ottawa: Author.

College of Registered Nurses of British Columbia (CRNBC). 2006. “New Graduate Registered Nurse Study - 2005." Vancouver: Author.

College of Registered Nurses of British Columbia (CRNBC). 2007."Nursing Schools." Retrieved September 25, 2008. <http://www.crnbc.ca/LearningCentre/NursingEd_FinancialResources/ NursingSchools.aspx $>$.

Dault, M., J. Lomas and M. Barer, on behalf of the Listening for Direction II Partners. 2004. "Listening for Direction II: National Consultation on Health Services and Policy Issues for 2004-2007: Final Report." Ottawa: Canadian Health Services Research Foundation. Retrieved September 25, 2008. <http://www.chsrf.ca/other_documents/listening/index2_e.php>.

Frontline Systems, Inc. 2007. Optimization Software for Excel, .NET, Java, MATLAB. Incline Village, USA. Retrieved September 25, 2008. <http://www.solver.com>.

Hillier, F.S. and G.J. Lieberman. 2001. Introduction to Operations Research (7th ed.). Boston: McGraw-Hill.

Human Resources and Skills Development Canada (HRSDC) BC/Yukon Region and BC Ministry of Advanced Education. 2005. "Work Futures BC Occupational Outlooks: Registered Nurses (NOC 3152).” Retrieved September 25, 2008. <http://www.workfutures.bc.ca/profiles/ profile.cfm?noc $=3152 \&$ lang $=$ en $\&$ site $=$ graphic $>$.

Kazanjian, A., K. Brothers and G. Wong. 1986. "Modeling the Supply of Nurse Labour. Life-Cycle Activity Patterns of Registered Nurses in One Canadian Delivery System." Medical Care 24(12): 1067-83.

Kephart, G., S. Maaten, L. O’Brien-Pallas, G. Tomblin Murphy and B. Milburn. 2004 (September). Building the Future: An Integrated Strategy for Nursing Human Resources in Canada. Simulation Analysis Report. Ottawa: The Nursing Sector Study Corporation. Retrieved September 
25, 2008. <http://www.cna-aiic.ca/CNA/documents/pdf/publications/simulation_analysis_ report_e.pdf $>$.

Kramer, M. and C. Schmalenberg. 2002. "Staff Nurses Identify Essentials of Magnetism.” In M. McClure and A. Hinshaw, eds., Magnet Hospitals Revisited: Attraction and Retention of Professional Nurses. Washington, DC: American Nurses Publishing.

Kramer, M., C. Schmalenberg and P. Maguire. 2004. "Essentials of a Magnetic Work Environment. Part 3." Nursing 34(8): 44-47.

Lavieri, M.S. and M.L. Puterman. 2008. "Optimizing Nursing Human Resource Planning in British Columbia." Manuscript submitted for publication.

O'Brien-Pallas, L., C. Alksnis and S. Wang. 2003. Bringing the Future into Focus. Projecting RN Retirement in Canada. Ottawa: Canadian Institute for Health Information.

O’Brien-Pallas, L., A. Baumann, G. Donner, G. Tomblin Murphy, J. Lochhaas-Gerlach and M. Luba. 2001. "Forecasting Models for Human Resources in Health Care." Journal of Advanced Nursing 33(1): 120-29.

Patrick, W.J. 2001. “Estimating First-Year Student Attrition Rates: An Application of Multilevel Modeling Using Categorical Variables." Research in Higher Education 42(2): 151-70.

Pringle, D. and L. Green. 2005. "The Pulse of Renewal: A Focus on Nursing Human Resources. Examining the Causes of Attrition from Schools of Nursing in Canada." Canadian Journal of Nursing Leadership. Retrieved September 25, 2008. <http://www.longwoods.com/product.php?pr oductid $=17477 \&$ page $=1>$.

Pringle, D., L. Green and S. Johnson. 2004 (December). Building the Future: An Integrated Strategy for Nursing Human Resources in Canada. Nursing Education in Canada: Historical Review and Current Capacity. Ottawa: The Nursing Sector Study Corporation. Retrieved September 25, 2008. <http://www.cna-aiic.ca/CNA/documents/pdf/publications/nursing_education_canada_e.pdf >. Romanow, R.J. 2002. Building on Values: The Future of Health Care in Canada. Final Report. Saskatoon: Commission on the Future of Health Care in Canada. Retrieved September 25, 2008. $<$ http://www.cbc.ca/healthcare/final_report.pdf >.

Scott, G. 2004. "Fines for High Student Attrition Rates." Nursing Standard 19(9): 5.

Statistics Canada. 2004. "Provinces and Territories. Live Birth Rate, Age-Specific, per 1000 Females in Age Range." Ottawa: Author.

Task Force Two. 2005. "A Physician Human Resource Strategy for Canada: Innovation Service Models in Canada Database." Ottawa: Author. Retrieved September 25, 2008. <http://www.physicianhr.ca/about/default-e.php>.

Villeneuve, M. and J. MacDonald. 2006. Towards 2020: Visions for Nursing. Ottawa: Canadian Nurses Association.

Weber, N. 2005. The Hidden Costs of RN Turnover. New York State Nurses Association. Retrieved September 25, 2008. <http://www.nysna.org/publications/report/2005/feb/turnover. htm $>$.

Wharrad, H.J., M. Chapple and N. Price. 2003. "Predictors of Academic Success in a Bachelor of Nursing Course." Nurse Education Today 23(4): 246-54. 